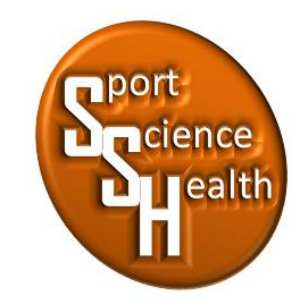

ISSN 2715-3886

\title{
Upaya Peningkatan Pukulan Backhand Clear Bulutangkis Menggunakan Metode Drill
}

\author{
Yefi Anggraini ${ }^{*}$, Oni Bagus Januarto², Rama Kurniawan ${ }^{3}$ \\ 1,2,3 Jurusan Pendidikan Jasmani, Kesehatan dan Rekreasi, Fakultas IImu Keolahragaan, \\ Universitas Negeri Malang, Jalan Semarang No 5, Malang, Jawa Timur, 65145, Indonesia \\ *Penulis koresponden: yefiyely@gmail.com, 082244837959
}

Artikel diterima: 30 Desember 2019; direvisi: 14 September 2020; disetujui: 18 September 2020

\begin{abstract}
The purpose of this study was to improve badminton backhand clear strokes in athletes aged 11-16 with a number of 11 male and 4 female PB. Eka Jaya Sidoarjo. This research is a type of sports action research (PTO). Data collection techniques used in this study were observation, interviews, questionnaires, documentation, and assessment instruments. The results of the study showed that the percentage of completeness in cycle 2 of the observers was $82.22 \%$. Based on the research results, it can be concluded that using the drill method can improve the backhand clear skills of PB athletes. Eka Jaya Sidoarjo.
\end{abstract}

Keyword: improvement, backhand clear, drill method

\begin{abstract}
Abstrak: Tujuan penelitian ini yaitu untuk meningkatkan pukulan backhand clear bulutangkis pada atletumur 1116 dengan jum lah yang di antaranya terdiri dari 11 putra dan 4 putri PB. Eka Jaya Sidoarjo. Penelitian ini merupakan jenis penelitian tindakan olahraga (PTO). Teknik pengumpulan data yang digunakan dalam penelitian ini adalah observasi, wawancara, angket, dokumentasi, dan instrumen penilaian. Hasil dari penelitian me nunjukkan persentase ketuntasan pada siklus 2 dari observersebanyak $82,22 \%$. Berdasarkan hasil penelitian maka dapat disimpulkan bahwa dengan menggunakan metode drill dapat meningkatkan keterampilan pukulan backhandclear pada atlet PB. Eka Jaya Sidoarjo.
\end{abstract}

Kata kunci: peningkatan, pukulan backhand clear, metode drill

\begin{abstract}
PENDAHULUAN
Kegiatan olahraga dikalangan masyarakat sangat umum dilakukan mulai usia muda, dewasa, hingga tua. Olahraga dilakukan sebagai saran latihan, rekreasi, Pendidikan, mata pencarian, hiburan, tontonan dan sebagai kebudayaan. Menurut Lundvall (2015) dan Sugden \& Wright (2014) bahwa kegiatan olahraga adalah upaya untuk membina jasmani dalam rangka memperoleh kebugaran dan kesehatan. Di Indonesia mulailah didirikan Persatuan Bulutangkis Seluruh Indonesia (PBSI) pada tanggal 5 Mei 1951 (Al Farisi, 2018; Maulina, 2018). Perkembangan bulutangkis Indonesia pada tahun 2016 sampai sekarang banyak mengalami peningkatan, seperti menyumbang medali diajang pertandingan internasional atau dunia. Sektor yang menjadi puncak prestasi bulutangkis ada di sektor ganda campuran, ganda putra, ganda putri, dan tunggal putra. Tahun 2017 sektor yang banyak menyumbang medali yaitu ganda putra. Semua itu tidak lepas dari kepelatihan yang baik dan benar. Di Kabupaten Sidoarjo terdapat suatu perkumpulan kepelatihan bulutangkis
\end{abstract}


untuk atlet yang masih pemula maupun yang sudah mahir. Tempat perkumpulan bulutangkis ini bernama PB. Eka Jaya Sidoarjo, lokasi berlatih PB. Eka Jaya Sidoarjo berada di desa Wringinanom Kelurahan Plos o Kec. Krembung Sidoarjo. PB. Eka Jaya Sidoarjo berdiri sejak tahun 2010 silam. Di klub PB. Eka Jaya jumlah total 25 atlet, terdiri atlet berusia 11-16 tahun berjumlah 15 orang dan atlet pemula usia 7-10 tahun berjumlah 15 orang. Kegiatan latihan bulutangkis di PB. Eka Jaya Sidoarjo dilaksanakan 6 kali latihan, adapun jadwal latihan yaitu hari Senin, Selasa, Rabu, Kamis, Sabtu, dan Minggu pukul 16.00 - 19.00. Untuk mendapatkan informasi mengenai keterampilan atlet PB. Eka Jaya Sidoarjo, peneliti melakukan pengamatan terhadap atlet PB. Eka Jaya pada tanggal 26 April 2019, berikut tampilan hasil pengamatan yang tersaji dalam tabel 1.

\begin{tabular}{rlcl}
\multicolumn{3}{c}{ Tabel 1. Data Hasil Observasi Permainan } & Bulutangkis di PB. Eka Jaya Sidoarjo \\
\hline NO. & Keterampilan Teknik & Total Nilai & $\begin{array}{l}\text { Persentase } \\
\text { keberhasilan }\end{array}$ \\
\hline 1. & Netting & 54 & $43,20 \%$ \\
2. & Smash & 60 & $48 \%$ \\
3. & Backhand Clear & 39 & $31,20 \%$ \\
4. & Forehand Lob & 71 & $56,80 \%$ \\
5. & Langkah Kaki & 70 & $56 \%$ \\
\hline
\end{tabular}

Hasil data yang dipaparkan pada tabel data di atas didapatkan dari hasil pengamatan permainan yang dilakukan oleh peneliti dibantu oleh pelatih, dan 1 observer berlisensi pada sesi program game dengan 11 point game lawan dengan sebanyak 15 atlet secara bergantian dengan cara jika pukulan dilakukan dengan benar, gerakan dilakukan dengan benar, shuttlecock masuk daerah lawan dan tepat sasaran menunjukkan bahwa keterampilan teknik pukulan berhasil atau jika pukulan salah, gerakan salah, dan shuttlecock keluar atau menyangkut net, maka teknik pukulan tersebut tidak berhasil.Untuk memperkuat hasil observasi awal, peneliti melakukan observasi lanjutan pada tanggal 27 April 2019 terkait keterampilan backhand clear. Berikut sajian data pada tabel 2 .

Tabel 2. Data Hasil Observasi Keterampilan Backhand Clear Dalam Permainan Bulutangkis di PB. Eka Jaya

\begin{tabular}{rlll}
\hline NO. & Teknik & Total Nilai & Persentase \\
\hline 1. & Sikap Persiapan & 23 & $85,15 \%$ \\
2. & Gerakan Memukul Shuttlecock & 20 & $74,07 \%$ \\
3. & Gerakan Lanjutan & 21 & $78 \%$ \\
\hline
\end{tabular}

Selain itu, dari hasil wawancara dengan pihak pelatih PB. Eka Jaya pada tanggal 29 April 2019, mengenai program latihan bulutangkis mengatakan bahwa pelatih hanya memberikan latihan stroke dan jarang menerapkan latihan metode drill dan yang sering diberikan saat latihan adalah pukulan forehand smash. Bapak Glewo juga mengatakan kurangnya pemberian model pelatihan pukulan backhand clear menjadi kendala untuk tingkat keberhasilannya, selain itu kepala pelatih PB. Eka Jaya Sidoarjo tersebut mengatakan setuju jika nantinya peneliti akan mengembangkan model-model pelatihan pukulan backhand clear menggunakan metode drill agar dapat meningkatkan keterampilan pukulan backhand clear atlet PB.Eka Jaya Sidoarjo. Observasi yang terakhir yang dilakukan peneliti berupa penyebaran angket kepada atlet PB. Eka Jaya Sidoarjo pada tanggal 29 april 2019 dengan hasil sebanyak 66,66\% (10 atlet) berlatih 6 kali dalam satu minggu, 80\% (12 atlet) berlatih 3 jam berlatih setiap pertemuan, 93,33 \% (14 atlet) perlu belajar pukulan backhand clear. 93,33\% (14 atlet) sangat tertarik dan ingin mempelajari materi pukulan backhand clear menggunakan metode drill. Proses perencanaan suatu program latihan haruslah mengacu kepada prosedur yang terorganisir dengan baik (well organized), yangmetodis, dan yang ilmiah, agar dengan demikian program tersebut bisa membantu atlet untuk mencapai prestasi yang setinggi - tingginya (Fattahudin, Januarto, \& Fitriady, 2020; Hendarto, Januarto, \& Tomi, 2020). Selama ini, kurangnya model latihan yang diberikan pelatih menjadi salah satu hambatan untuk keberhasilan melalukan pukulan backhan clear. Cohen, Texier, Quéré, \& Clanet (2015) dan Phomsoupha \& Laffaye (2015) menjelaskan bahwa secara biomekanik, Teknik pukulan ini menuntut koordinasi anggota badan yang sempurna serta penguasaan grip dan timing yang tepat. Tanpa ketiga hal tersebut, tenaga yang besar sekali pun tidak akan bisa menghasilkan kualitas pukulan yang baik. Pelatihan bulutangkis untuk memperoleh keterampilan dan mencapai prestasi tinggi dalam permainan bulutangkis diperlukan proses latihan dengan melatih banyak faktor yang harus ditingkatkan, dilakukan secara 
metodologis, canggih, memerlukan waktu, dan melibatkan banyak unsur (Butterworth, Turner, \& Johnstone, 2012; Ozmen \& Aydogmus, 2016).

Berdasarkan permasalahan yang telah diuraikan, peneliti melakukan penelitian tindakan olahraga. Penelitian ini untuk meningkatkan keterampilan pukulan backhand overhead clear pada atlet bulutangkis melalui penelitan yang berjudul "Upaya Peningkatan Pukulan Backhand Clear Menggunakan Metode Drill'. Berdasarkan rumusan masalah yang telah diuraikan, maka tujuan yang ingin dicapai adalah untuk dapat meningkatan pukulan backhand clear bulutangkis pada atlet PB. Eka Jaya Sidoarjo.

\section{METODE}

Pada penelitian ini menggunakan penelitian tindakan olahraga (PTO), tujuan dari diadakan penelitian ini yaitu dapat meningkatkan pukulan backhand clear bulutangkis pada atlet usia 11-16 tahun PB. Eka Jaya Sidoarjo yang terdiri dari 11 atlet putra dan 4 atlet putri dengan melakukan observasi keadaan di lapangan. Dilihat dari tujuan penelitian ini adalah penelitian tindakan olahraga (PTO), penelitian ini memiliki kesamaan dengan penelitian tindakan kelas (PTK), yaitu tetap megikuti dasar landasan pada penelitian tindakan. Menurut Fikri, (2017) dan Hidayat (2017) berpendapat bahwa perbedaan terletak pada substansi masalah peneliti dan konsep kelasnya. Pelaksanaan rancangan siklus PTK dalam kepelatihan olahraga masih sama mengikti langkah-langkah PTK. Sama halnya dengan yang dikemukakan bahwasanya penelitian tindakan olahraga dengan penelitiian tindakan kelas sama-sama melewati beberapa tahapan yakni perencanaan, pelaksanaan, pengamatan dan juga refleksi (Effendi \& Rhamadhansyah, 2017; Mohamad N, Budiman, \& Suhendi, 2016). PTO memiliki perbedaan yang jelas diantaranya yaitu PTO memiliki substansi yang lebih mengarah pada peningkatan keterampilan motorik olahraga yang dinaungi sedangkan PTK lebih mengarah untuk meningkatkan kualitas pembelajaran. PTK sendiri memiliki konsep kelas yang bebas bisa di lapngan, kelas, ataupun alam, sedangkan PTO memiliki konsep kelas yang terpaku pada cabang olahraga itu sendiri.

Berdasarkan beberapa perbedaan yang telah disebutkan dapat dipahami bahwasanya ada perbedaan antara PTO dan PTK yang terletak pada substansi dan konsep kelasnya. Kehadiran peneliti pada penelitian ini adalah sebagai observer dimana kegunaan observer adalah untuk mengamati proses latihan dan kesalahankesalahan mulai dari perencanaan awal sampai refleksi. Selain itu dalam proses latihan kehadiran peneliti sebagai patner pelatih untuk bekerja sama memecahkan masalah dengan membuat konsep tindakan yang dilakukan bersama-sama yaitu peneliti dan juga pelatih sehingga dengan adanya hal ini peneliti merasakan langsung adanya suatu masalah yang diperlukannya solusi dalam memecahkan masalah tersebut.

Penelitian tindakan olahraga diaksanakan di PB. Eka Jaya Sidoarjo yang dilaksanakan di Gedung Latanza Desa Wringinanom Kelurahan Ploso, Kecamatan Krembung, Kabupaten Sidoarjo. Subjek pada penelitian ini adalah tlet usia 11-16 tahun yang terdiri dari 11 atlet putra dan 4 atlet putri. Data yang dikumpulkan mengenai latihan metode drill pukulan backhand clear yang didapatkan dari hasil observasi pengamatan pada saat proses pelatihan dan hasil angket serta wawancara dengan pelatih. Observasi atau yang disebut, meliputi permuatan perhatian terhadap suatu objek dengan menggunakan seluruh alat indra (Jamshed, 2014; Zhang et al., 2017). Didalam arti penelitian observasi dapat dilakukan dengan tes, kuisioner, rekaman gambar, dan rekaman suara.

Tabel 3. Analisis Persentase (Kafle, 2013; Van Hoecke, 2016)

\begin{tabular}{lll}
\hline Persentase & Keterangan & Makna \\
\hline $81 \%-100 \%$ & Sangat Baik & Digunakan \\
\hline $61 \%-80 \%$ & Baik & Digunakan \\
\hline $41 \%-60 \%$ & Cukup & Digunakan \\
\hline $21 \%-40 \%$ & Kurang & Diperbaiki \\
\hline $05-20 \%$ & Kurang Sekali & Diganti \\
\hline
\end{tabular}

HASIL

Hasil penelitian ini akan dpaparkan dari data hasil yang diperoleh peneliti pada tahap observasi awal sampai dengan proses pelaksanaan penelitian. Observasi awal dilakukan peneliti bersama pelatih dengan melakukan program game dengan poin 11 kemenangan secara bergantian. Dari hasil tersebut dapat diketahui bahwa 
keberhasilan teknik pukulan netting sebanyak $43,20 \%$, teknik pukulan smash sebanyak $48 \%$ keberhasilan, teknik pukulan backhand clear sebanyak 31,20\% keberhasilan, teknik pukulan forehand lob sebanyak 56,80\% keberhasilan, teknik langkah kaki sebanyak $56 \%$ keberhasilan. Berdasarkan hasil tersebut, maka peneliti mengamati keterampilan pukulan backhand clear dan diperoleh hasil persentase keberhasilan pada indikator gerakan memukul shuttlecock sebanyak $31,20 \%$ keberhasilan. Kesimpulan yang dapat diambil adalah bahwa teknik pukulan backhand clear menjadi kelemahan pada atlet PB. Eka Jaya Sidoarjo.

Dari hasil wawancara dengan pelatih mengatakan bahwa pelatih hanya memberikan latihan stroke dan jarang menerapkan latihan metode drill dan yang sering diberikan saat latihan adalah pukulan forehand smash. Pelatih juga mengatakan kurangnya pemberian model pelatihan pukulan backhand clear menjadi kendala untuk tingkat keberhasilannya Berdasarkan refleksi awal, maka peneliti dan pelatih membuat program latihan dan catatan lapangan. Hasil dari siklus 1 dan siklus 2 menunjukkan adanya perbedaan peningkatan. Pada siklus 1 persentase peningkatan ketuntasan sebanyak 38,30\%, sedangkan siklus 2 persentase peningkatan ketuntasan menunjukkan sebanyak $70,47 \%$. Dari hasil latihan pada siklus 2 , telah terjadi peningkatan yang sudah mencapai $82,22 \%$.

\section{PEMBAHASAN}

PB. Eka Jaya Sidoarjo terletak di Desa Wringinanom Kelurahan Ploso, Kecamatan Krembung, Kabupaten Sidoarjo memiliki 25 atlet yang terdiri dari 15 atlet berusia 11-16 tahun dan 10 atlet pada usia 7-10 tahun. Pada tanggal 26 April 2019 peneliti melakukan pengamatan dengan menggunakan program gamedengan poin 11 kemenangan secara bergatian. Pengamatan dilakukan peneliti untuk mengetahui teknik apa saja yang masih kurang dikuasai oleh atlet. Menurut Patterson, Pattison, Legg, Gibson, \& Brown (2017) dan Rusydi, Sasaki, Sucipto, Zaini, \& Windasari (2015) bahwa unsur-unsur dalam permainan bulutangkis terdiri dari beberapa teknik antara lain yaitu teknik tanpa bola, sikap siaga, teknik pegang raket, teknik kerja kaki, teknik pukulan, teknik pukulan servis yang terdiri dari servis melambung, dan servis pendek, teknik pukulan overhead lob, forehand lob, backhand lob, teknik pukulan overhead dropshot, dropshot lambat, dropshot cepat, teknik pukulan smash yang terdiri dai smash penuh, smash setengah, teknik pukulan net drop dan teknik pukulan mendatar (drive).

Berdasarkan hasil tes permainan yang dilakukan peneliti dan dibantu oleh pelatih yang mana melibatkan 15 atlet usia 11-16 tahundi PB. Eka Jaya Sidoarjopada 26 April 2019 menggunakan program game 11 poin kemenangan secara bergantian. Hasil data yang didapatkan berupa teknik pukulan netting sebanyak $43,20 \%$ keberhasilan, teknik pukulan smash sebanyak $48 \%$ keberhasilan, teknik pukulan backhand clear sebanyak $31,20 \%$ keberhasilan, teknik pukulan forehand lob sebanyak $56,80 \%$ keberhasilan, teknik langkah kaki sebanyak $56 \%$ keberhasilan. Peneliti dapat menyimpulkan bahwa teknik pukulan backhand clear menjadi kelemahan pada atlet PB. Eka Jaya Sidoarjo. Dari hasil pengamatan keterampilan yang telah dilaksanakan peneliti dan pelatih dengan 15 atlet usia 11-16 tahun di PB. Eka Jaya Sidoarjo, kesulitan yang sering terlihat pada atlet saat melakukan pukulan backhand clear pada indikator Gerakan memukul shuttlecock sebanyak $31,20 \%$ keberhasilan. Berdasarkan hasil wawancara dengan pelatih yang mengatakan bahwa pelatih hanya memberikan latihan stroke dan jarang menerapkan latihan metode drill dan yang sering diberikan saat latihan adalah pukulan forehand smash. Bapak Glewo juga mengatakan kurangnya pemberian model pelatihan pukulan backhand clear menjadi kendala untuk tingkat keberhasilannya, selain itu kepala pelatih PB. Eka Jaya Sidoarjo tersebut mengatakan setuju jika nantinya peneliti akan mengembangkan model-model pelatihan pukulan backhand clear menggunakan metode drill agar dapat meningkatkan keterampilan pukulan backhand clear atlet PB.Eka Jaya Sidoarjo.

Dari hasil penyebaran angket yang dilaksanakan pada tanggal 09 Mei 2019 untuk 15 atlet berusia 11-16 tahun di PB. Eka Jaya Sidoarjo, (1) 66,66 \% (10 atlet) berlatih 6 kali dalam satu minggu, 80\% (12 atlet) berlatih 3 jam berlatih setiap pertemuan, (2) 93,33\% (14 atlet) perlu belajar pukulan backhand clear. (3) 93,33\% (14 atlet) sangat tertarik dan ingin mempelajari materi pukulan backhand clear menggunakan metode drill. Berdasarkan hasil pengamatan yang dilaksanakan pada hari Sabtu 02 November 2019, Senin 04 November 2019, Rabu 06 November 2019, Kamis 07 November 2019, Sabtu 09 November 2019. Latihan di mulai jam 16.00-19.00 WIB bertempat di Gedung Latanza Desa Wringinanom Kelurahan Ploso Kec. Krembung Sidoarjo. Data yang ditemukan sebagai berikut. 
Tabel 4. Data Hasil Tindakan Siklus 1

\begin{tabular}{llll}
\hline & \multicolumn{2}{l}{ Gerakan Teknik Pukulan Backhand Clear Bulutagkis } \\
\hline & Sikap Persiapan & Sikap Memukul & Sikap Lanjutan \\
\hline (Observer ) & $57,77 \%$ & $55,55 \%$ & $60 \%$ \\
\hline $\begin{array}{l}\text { (Observasi) } \\
\begin{array}{l}\text { Ketuntasan } \\
\text { Keseluruhan (\%) }\end{array}\end{array}$ & $57,77 \%$ & & \\
\hline
\end{tabular}

Dari hasil pengamatan yang dilaksanakan pada hari Rabu 13 November 2019, Kamis 14 November 2019 , Sabtu 16 November 2019, Senin 18 November 2019, Rabu 20 November 2019. Latihan di mulai jam 16.00 19.00 WIB bertempat di Gedung Latanza Desa Wringinanom Kelurahan Ploso Kec. Krembung Sidoarjo. Data yang ditemukan sebagai berikut.

Tabel 5. Data Hasil Tindakan Siklus 2

\begin{tabular}{llll}
\hline & \multicolumn{3}{l}{ Gerakan Teknik Pukulan Backhand Clear Bulutagkis } \\
\hline & Sikap Persiapan & Sikap Memukul & Sikap Lanjutan \\
\hline (Observer ) & $84,44 \%$ & $82,22 \%$ & $80 \%$ \\
\hline $\begin{array}{l}\text { (Observasi) } \\
\text { Ketuntasan Keseluruhan } \\
(\%)\end{array}$ & $82,22 \%$ & & \\
\hline
\end{tabular}

\section{KESIMPULAN}

Berdasarkan dari hasil penelitian tindakan olahraga yang dilaksanakan untuk peningkatan pukulan backhand clear bulutangkis dapat disimpulkan bahwa dengan menggunakan model latihan metode drilldapat meningkatkan keterampilan pukulan backhand clear bagi atlet PB. Eka Jaya Sidoarjo.

\section{DAFTAR PUSTAKA}

Al Farisi, M. A. H. (2018). Model Latihan Kelincahan Bulutangkis. Jurnal Segar.

Butterworth, A. D., Turner, D. J., \& Johnstone, J. A. (2012). Coaches' perceptions of the potential use of performance analysis in badminton. International Journal of Performance Analysis in Sport. https://doi.org/10.1080/24748668.2012.11868610

Cohen, C., Texier, B. D., Quéré, D., \& Clanet, C. (2015). The physics of badminton. New Journal of Physics. https://doi.org/10.1088/1367-2630/17/6/063001

Effendi, A. R., \& Rhamadhansyah, F. (2017). Peningkatan Pembelajaran Menggiring Bola. Jurnal Pendidikan Olahraga.

Fattahudin, M. A., Januarto, O. B., \& Fitriady, G. (2020). Upaya Meningkatkan Keterampilan Pukulan Forehand Smash Bulutangkis Dengan Menggunakan Model Variasi Latihan Untuk Atlet Usia 12-16 Tahun. Sport Science Health, 2(3), Retrieved 182-194. from http://journal2.um.ac.id/index.php/jfik/article/view/11493/5421

Fikri, A. (2017). Meningkatkan Kebugaran Jasmani Melalui Metode Latihan Sirkuit Dalam Pembelajaran Pendidikan Jasmani Olahraga Dan Kesehatan Di Sma Negeri 1 Lubuklinggau. Jurnal Pembelajaran Olahraga.

Hendarto, M. H., Januarto, O. B., \& Tomi, A. (2020). Meningkatkan Backhand Overhead Clear Bulutangkis Dengan Metode Drill. Sport Science and Health, 2(4), 232-238. Retrieved from http://journal2.um.ac.id/index.php/jfik/article/view/11685/5575

Hidayat, A. (2017). Peningkatan Aktivitas Gerak Lokomotor, Nonlokomotor Dan Manipulatif Menggunakan 
Model Permainan Pada Siswa Sekolah Dasar. Jurnal Pendidikan Jasmani Dan Olahraga. https://doi.org/10.17509/jpjo.V2i2.8175

Jamshed, S. (2014). Qualitative research method-interviewing and observation. Journal of Basic and Clinical Pharmacy. https://doi.org/10.4103/0976-0105.141942

Kafle, N. P. (2013). Hermeneutic phenomenological research method simplified. Bodhi: An Interdisciplinary Journal. https://doi.org/10.3126/bodhi. v5i1.8053

Lundvall, S. (2015). Physical literacy in the field of physical education - A challenge and a possibility. Journal of Sport and Health Science. https://doi.org/10.1016/j.jshs.2015.02.001

Maulina, M. (2018). Profil Antropometri Dan Somatotipe Pada Atlet Bulutangkis. AVERROUS: Jurnal Kedokteran Dan Kesehatan Malikussaleh. https://doi.org/10.29103/averrous.v1i2.413

Mohamad N, I., Budiman, D., \& Suhendi, H. (2016). Penerapan Modifikasi Alat Untuk Meningkatkan Keterampilan Bermain Bulutangkis (Penelitian Tindakan Kelas di SD Percobaan Negeri Setiabudi Bandung). Jurnal Pendidikan Jasmani Dan Olahraga. https://doi.org/10.17509/jpjo.v1i2.5665

Ozmen, T., \& Aydogmus, M. (2016). Effect of core strength training on dynamic balance and agility in adolescent badminton players. Journal of Bodywork and Movement Therapies. https://doi.org/10.1016/j.jbmt.2015.12.006

Patterson, S., Pattison, J., Legg, H., Gibson, A. M., \& Brown, N. (2017). The impact of badminton on health markers in untrained females. Journal of Sports Sciences. https://doi.org/10.1080/02640414.2016.1210819

Phomsoupha, M., \& Laffaye, G. (2015). The Science of Badminton: Game Characteristics, Anthropometry, Physiology, Visual Fitness and Biomechanics. Sports Medicine. https://doi.org/10.1007/s40279-0140287-2

Rusydi, M. I., Sasaki, M., Sucipto, M. H., Zaini, \& Windasari, N. (2015). Local Euler Angle Pattern Recognition for Smash and Backhand in Badminton Based on Arm Position. Procedia Manufacturing. https://doi.org/10.1016/j.promfg.2015.07.125

Sugden, D., \& Wright, H. (2014). Physical education. In Enabling Access: Effective Teaching and Learning for Pupils with Learning Difficulties. https://doi.org/10.4324/9781315067780-12

Van Hoecke, M. (2016). Methodology of Comparative Legal Research. Law and Method. https://doi.org/10.5553/rem/.000010

Zhang, J., Hess, P. W., Kyprianidis, A., Becker, P., Lee, A., Smith, J., .. Monroe, C. (2017). Observation of a discrete time crystal. Nature. https://doi.org/10.1038/nature21413 